International Journal on Information Sciences and Computing, Vol. 4, No.2, July 2010

\title{
EMOTIONAL COMPETENCIES IN TEAM AND IT'S RELATIONSHIP WITH TEAM EFFECTIVENESS
}

\author{
Akila $\mathbf{R}^{1}{ }^{\text {, Thangavel }} \mathbf{N}^{2}$ \\ ${ }^{1}$ Sr Lecturer, Dept. of Mgt Studies, Jeppiaar Engg College, Chennai \\ 2 Principal (PG Studies), Jeppiaar Engg College, Chennai \\ Email: akila.sr@gmail.com, thangavelraj@gmail.com
}

\begin{abstract}
In this challenging knowledge era work teams have been described as basic integral for organizational success. The use of teams has become very popular global strategy and a number of MNC has also implemented teams in their organization. The major reason for developing team culture in the organization is that it provides certain organizational benefits, such as the improvement of team performance, productivity, and cost reduction and employee satisfaction. However not all teams are the ones of high efficiency. Many researchers argue that there are some influential factors for the improvement of team's effectiveness. Among various influential factors of team effectiveness, emotion and emotional behavior are considered to be important factors that affect team effectiveness. Druskat and wolff proposed a model of how emotions and emotional behaviours are manifested in group and how the behavioural norms that are established in a group affect the group's performance. The proposed behavioural norms are labeled emotionally competent group norms( ECGN). These norms have been linked to team performance. This study was done to examine whether the emotionally competent group norms in a team affect the team effectiveness.
\end{abstract}

Key word: Team, Performance, Effectiveness, ECGN, Behavioural Norms

\section{INTRODUCTION}

In today's competitive, fast paced, customer driven business environment, organization has to struggle to achieve success. A variety of forces like consolidation, innovation, cut throat competition create pressure for skill diversity, high level expertise, and adaptability. These challenges forced managers to transform the actual structure of traditional, hierarchical management into flattered and flexible structure with interactive, interdependent and creative processes. So organizations are redesigning their work from individual jobs in functionalized structure to small teams based structure. The major reason for developing team culture in the organization is that it provides certain organizational benefits, such as the improvement of team performance, productivity, cost reduction and employee satisfaction. And some other researchers also indicate that team operation can promote organizational efficiency, such as learning efficiency, innovation capability, working process and quality management.

However not all teams are the ones of high efficiency. Many researchers argue that there are some influential factors for the improvement of team's effectiveness. Among various influential factors of team effectiveness emotion and emotional behavior are considered to be important factors that affect team effectiveness. Much research was not done on emotion within a team and effects of emotions on team performance. Druskat and wolff proposed a model of how emotions and emotional behaviours are manifested in group and how the behavioural norms that are established in a group affect the group's performance. The proposed behavioural norms are labeled emotionally competent group norms( ECGN). These norms have been linked to team performance. This study was done to determine the relationship between the emotionally competent group norms in a team and team effectiveness.

\subsection{LITERATURE REVIEW:}

\subsubsection{Team}

A team can be defined as two or more individuals who are socially interact and share one or more common goals. They are brought together to perform organizationally relevant tasks. They exhibit interdependencies with respect to workflow, goals, and outcomes. They have different roles and responsibilities and together embedded in an encompassing organizational system. According Katzenbach and smith team is composed of several mutual favoring people to achieve the common goal and fulfill the common 
responsibility. Jessup argues that a team needs interdependence and inter-commitment among team members to achieve common goal. Similarly Jessup and shonk also argues that team has to satisfy to these three conditions. 1. Composed of more than two members. 2. Stressing interdependence and coordination among team members to achieve working goal and 3. Team members are encouraged to achieve common goal. Lewis defines that team is just an identification group in pursuit of common goal. The group guides its members to get along well with each other and work happily together, purposing to encourage them to achieve high quality performance. Some researcher's opinion on team are expressed from the performance perspective. They argue that team member should take the full responsibility for the success or failure of work, and that the behaviour of the whole team decides the performance and rewards of members. Hackman argues that internally team member should clearly know the common goal, decide working schedule get achievement of work, make relevant arrangement and assign mission. The feedbacks of reward and performance can be reflected from the behaviour of the whole team.

From the various studies about the team, it can be concluded that a team is a working unit composed of more than two members who stress interdependence and cooperation with each other, pursue common goal and take the responsibility for the success or failure of work. The growing significance of the teams demands the need for understanding the factors which affect team and its performance. This study examines the influence of the emotional intelligence group level norms that established on team on team performance.

\subsubsection{Emotional Intelligence and Team}

Although there is a lot of literature on individual emotion and on emotional intelligence, there is a gap in the literature on the effects of emotion and emotional intelligence in teams and work groups. Many human emotions grow from social interactions of groups. Thus emotions are an important component of teams and have been identified as having an impact on a group's success. In any situation the expression of behaviour is moderated by cultural norms. Norms has been defined as the ideas or expectation about appropriate behaviour for system members. The norms within a group can act as forces to control or constrain member's behaviors. Thus norms affect the cognitive processes for group members to anticipate the behaviour of others and to make appropriate responses that support group survival and success. Group emotion operates at multiple levels this was explained by Barsade and Gibson as interpersonal, group and intergroup relationship levels. Wolff and druskat have identified the existence of group level competencies which reflect the group's ability to generate group norms that influences and manage the emotional process in a way that builds emotional capacity and develops social capital and leads to effectiveness. These group norms help to determine if a group of individual functions as a high performing team. Wolff and Druskat state that each of the ECG norms is related to the individual, group or cross boundary group emotion level.

\section{Table 1. Wolff and Druskat's ECGN classification of Norms}

\begin{tabular}{|c|c|c|}
\hline Levels & Dimensions & Norms \\
\hline \multirow[t]{3}{*}{\begin{tabular}{|l|} 
Individual \\
\end{tabular}} & $\begin{array}{l}\text { Group awareness } \\
\text { of members }\end{array}$ & \begin{tabular}{|l} 
Interpersonal \\
Understanding
\end{tabular} \\
\hline & \multirow[t]{2}{*}{$\begin{array}{l}\text { Group } \\
\text { management of } \\
\text { members }\end{array}$} & $\begin{array}{l}\text { Confronting } \\
\text { members who break } \\
\text { norms }\end{array}$ \\
\hline & & Caring behaviour \\
\hline \multirow[t]{4}{*}{ Group } & $\begin{array}{l}\text { Group Self } \\
\text { awareness }\end{array}$ & Team Self Evaluation \\
\hline & \multirow[t]{3}{*}{$\begin{array}{l}\text { Group Self } \\
\text { management }\end{array}$} & $\begin{array}{l}\text { Creating Resources } \\
\text { for working with } \\
\text { emotion }\end{array}$ \\
\hline & & $\begin{array}{l}\text { Creating an } \\
\text { affirmative } \\
\text { environment }\end{array}$ \\
\hline & & $\begin{array}{l}\text { Proactive problem } \\
\text { solving }\end{array}$ \\
\hline \multirow[t]{2}{*}{$\begin{array}{l}\text { Cross } \\
\text { Boundary }\end{array}$} & $\begin{array}{l}\text { Group Social } \\
\text { awareness }\end{array}$ & $\begin{array}{l}\text { Organizational } \\
\text { Understanding }\end{array}$ \\
\hline & $\begin{array}{l}\text { Group } \\
\text { Management Of } \\
\text { external } \\
\text { Relationship }\end{array}$ & $\begin{array}{l}\text { Building external } \\
\text { relationships }\end{array}$ \\
\hline
\end{tabular}




\subsubsection{Team Effectiveness}

Organization expects to improve team effectiveness by strengthening the team performance. Most of the researches study team effectiveness through the measurement of team performance. There are many models and theories about team effectiveness. Katzenbach and smith claim that the most important determinant of team performance is having a specific performance challenge that is clear and compelling to all team members. Dyer suggested other criteria of effective teams. His research on organizational work teams showed the following characteristics of effective teams.

- Goals and values are clear, they are understood and accepted by everyone.

- People understand their assignments and the ways their roles contribute to the work on the whole.

- The basic climate is one of trust and support among members.

- Communications are open. People are willing and have high personal performance standards.

- Differences are recognized and handled, not ignored or brushed over lightly.

- The team structure and procedures are consistent with the task, goals, and people involved.

McGrath developed a framework for studying group performance consisting of inputs, process and outputs. Druskat and wolff also discussed team performance in terms of interaction and noted that these take place at multiple levels. They asserted that teams must be mindful of the emotions of its members, its own group emotions or moods and the emotions of other groups and individual outside its boundaries. Emotional intelligence according to Druskat and Wolff, enabled teams to establish norms for group maintenance behaviour. Optimal team performance depended on emotionally intelligent norms the attitudes and behaviours that become habits - that support behaviours for buiding trust, group identity, and group efficacy.

\subsection{Need of the Study;}

Since the IT companies today primarily incorporate the team culture into their functioning, the management wanted to evaluate and improve the effectiveness of teams. This research will help corporation to improve performance to their desired level.

\subsection{Objective of the Study:}

- To study the relationship between team ECGN and team effectiveness.

- To study whether teams with higher ECGN will outperform teams with low ECGN.

\subsection{Hypothesis of the study :}

- There is a positive linear relationship between individual level ECGN presence and team effectiveness.

- There is a positive linear relationship between group level ECGN presence and team effectiveness.

- There is a positive linear relationship between cross boundary level ECGN presence and team effectiveness.

\section{RESEARCH METHODOLOGIES}

\section{Research Design}

The research design used for the study is descriptive since the study aimed to describe the relationship between ECG Norms and the team effectiveness.

\section{Population:}

The population of the study consists of the teams working in BPO services. The teams which are working with specific client and performing similar nature of work.

\section{Sample size:}

The sample size of the study consisted of 30 teams.

\section{Sampling Technique:}

The sampling technique used was convenience sampling

\section{Data Collection Method;}

Primary data was collected through
questionnaires which were administered by the
researcher personally.




\section{Instrument Design;}

The emotional intelligence of the team was measured using the Emotionally competent group norms scales ( Hamme, 2003). The ECGN scales consist of 57 questions representing nine ECG norms. Each competency represents one of three ECGN clusters. Each cluster has an awareness and regulation competency on the individual, group and cross boundary levels. The nine scales were comprised of 5-8 questions, with one to three in each scale reversed scored. Respondents rated each item on a one to seven likert scale ranging from very inaccurate to very accurate.

The team effectiveness was measured using 5 item questionnaire developed and tested by Drusakat ,koman, messer and wolff, (2003). The parameters evaluated are efficiency in getting things done, quality of work, ability to be self directed, performance against other teams that perform similar work, and ability to continue working together in the future.

\section{Data Analysis Tools:}

- Statistical tools

* Reliability and Validity Study

* Inferential statistics such as Chi-square Test, Factor Analysis

* Correlation \& Regression analysis

* Descriptive Statistics, Charts and Graphs

\section{RESULTS}

The hypotheses formulated were tested using correlation and regression analysis. Hypothesizes is partially supported. Each level of ECGN was correlated with the effectiveness rating. The cross boundary level was significantly correlated with team effectiveness scores. This is explained in Table No 1.

Table 2 ECGN and performance correlation

\begin{tabular}{|l|c|c|}
\hline \multirow{2}{*}{ ECGN Level } & \multicolumn{2}{c|}{ Performance } \\
\cline { 2 - 3 } & $r$ & $p$ \\
\hline Individual & 0.176 & 0.138 \\
\hline Group & 0.176 & 0.045 \\
\hline Cross Boundary & 0.578 & 0.289 \\
\hline
\end{tabular}

From this study it is clear that there is a relationship between ECGN and team effectiveness. In the past research the researcher tried to relate the ECGN as whole to the team effectiveness. In this research nine norms of ECG was related to team effectiveness.

\section{Correlation between ECGN and team effectiveness measures}

Interpersonal Understanding

Confronting members who break norms

Caring Behaviour

Team Self Evaluation

Creating Resources for working with

0.005

emotion

Creation an affirmative environment

Proactive problem solving

Organisational Understanding

Building External relationships

When the nine ECGN were examined independently they were all found to be significantly related to team effectiveness at 0.5 level. The interpersonal understanding, creation of affirmative environment, Proactive problem solving, building external relationships were found to be significantly related to performances measures than the other norms.

The last research objective which examine whether teams with higher ECGN will out perform those with lesser collective ECGN was tested by correlating the team ECGN score and the managers score on the team performance. The result proves that team with high scores on ECGN secured the high rating from the managers for performance. So it can be inferred that team with high ECGN can out perform those with lesser ECGN.

\section{IMPLICATION OF THE STUDY TO THE INDUSTRY}

The results and implications of the study are very significant for the industries. The knowledge of the study will help the MNC to improve performance by developing emotionally competent work group. This study supports the strategy of developing emotionally 
competent group norms throughout an organization to attain and sustain high performing work teams.

\section{CONCLUSION}

This study proves the Wolff and Druskat ECGN theory. This study also partially support that ECGN has significant relation with group effectiveness. When the relationship between each ECG norms examined individually the interpersonal understanding, creation of affirmative environment, proactive problem solving, building external relationships were found to be significantly related to performances measures at the .05 level in every subset of the sample. The other norms seem to be not much related to the performance, the reason could be the sample and its size. This study enlightens us about the emotions in groups and in the workplace. It is understood from this study that team climate will affect the team outcomes.

\section{REFERENCES:}

[1] Katzenbach,J.R and smith, D.K, (1993) "The wisdom of teams" Harvard Business School Press.

[2] Alison Hardingham \& jerry Royal, Team work in practice. (1990), Human Factors, 34, 277-288

[3] Chia Chen Kuo, Research on impacts of team leadership on team effectivness, The Journal of American Academy of business, cambrige- Pg 266-276

[4] John E. Mathieu and lucy L.Gilson, Thomas M.Reddy Empowerment and team effectiveness: An empirical Test of an integrated Model., Journal of Applied Psychology, 2006, Vol 91 no1 Pg 91-108
[5] Steven B.Wolff, Vanessa Urch Druskat, The Link between emotions and team effectivness: How teams engage members and build effective task processes, Academy of management proceedings,

[6] Jeffery A. Lepine, Ronald F. Piccolo, Christine L. Jackson, A Meta-Analysis Of Teamwork Processes: Tests Of A Multidimensional Model And Relationships With Team Effectiveness Criteria, Personnel Psychology, 2008, 61, 273-307.

[7] Anne E Feyerherm, Cheryl L.Rice, Emotional Intelligence And Team Performance: The Good, The Bad And The Ugly, The International Journal Of Organisational Analysis, 2002, Vol. 10. 4 pp 343 -362.

[8] Elizabeth Christine Stubbs, "Emotional Intelligence competencies in the team and team Leader: Multi level examination of the impact of emotional intelligence on group performance"

[9] B.A.Rapisarda "The impact of emotional intelligence on work team" The international journal of organizational anlaysis Vol no 4,200.

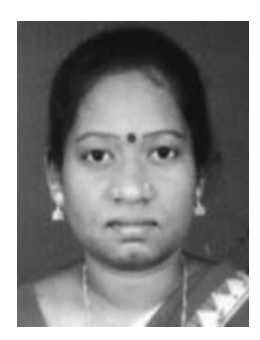

Mrs.R.Akila working as $\mathrm{Sr}$ lecturer in MBA Dept of Jeppiaar Engineering College. She is having about 12 yrs teaching experience. She has presented 17 papers in international and national conference. She is also pursuing her Ph.D ( HRM) in Mother Teresa Women's University Kodaikanal. 